\title{
Kinetic Study of Air Bubbles-Cetyltrimethylammonium Bromide (CTAB) Surfactant for Recovering Microalgae Biomass in a Foam Flotation Column
}

\author{
Muayad A. Shihab ${ }^{1 *}$, Mohammed A. Dhahir ${ }^{1}$, Hamad K. Mohammed ${ }^{1}$ \\ 1 Petroleum and Gas Refinery Engineering, College of Petroleum Process Engineering, Tikrit University, Slah \\ Al-deen, 34001, Iraq
}

\begin{abstract}
Owing to their efficient photosynthesis, microalgae tend to possess superior growth rates and high lipid production, hence their significance to the biofuel sector. The bulk harvesting of microalgae from cultures is a substantial stage in advancing the production of biomass-based fuels. However, a reliable and cost-effective harvesting technology is not yet available. Foam flotation, which is a subcategory of the adsorptive bubble separation process, shows considerable promise for the harvesting and enrichment of microalgae biomass. The available literature indicates that virtually no data has been reported on the flotation kinetics of microalgae. Therefore, to better describe the recovery of microalgae by the flotation process, this work studied the flotation kinetics of the freshwater microalgae Chlorella vulgaris. The recovery of microalgae cells in a batch foam flotation column over time at different operating conditions was fitted to nine flotation kinetic models, including first, fractional, and second order kinetic models; a first order kinetic model with rectangular, exponential, gamma, and sinusoidal distributions of floatabilities; a second order kinetic model with rectangular distribution of floatabilities; a fully mixed reactor; and modified Kelsall flotation kinetic models. Evaluation of the kinetic models showed that the discrete rate constant model (i.e. modified Kelsall kinetic model) fitted the experimental data best. The modified Kelsall model shows the highest values of adjusted $\mathrm{R}^{2}(>0.995)$ and the lowest values of mean squared error $(<2.63)$. Apart from the modified Kelsall model, which has discrete rate constants, no single kinetic model, with or without a continuous distribution, was sufficient to represent the flotation data, and the optimal model may vary under different conditions. More work is recommended using different freshwater and marine microalgae species.
\end{abstract}

Keywords: Biofuel; Chlorella vulgaris; Foam flotation; Kinetic rate constant; Ultimate recovery

\section{Introduction}

Due to concerns about the sustainability of fossil fuel, environmental pollution, and global climate change, enormous attention has been given over the last two decades to renewable energy resources, like microalgae. The growing interest in microalgae is due to their superior growth rates, high lipid production, and ability to be cultivated everywhere (Cercado et al., 2018; Sukarni et al., 2019; Rizaldi et al., 2019). The bulk harvesting of microalgae from cultures is a substantial stage in advancing the production of biomassbased fuels, but a reliable and cost-effective harvesting technology is not yet available. Foam flotation, which is a subcategory of the adsorptive bubble separation process, shows notable promise for the harvesting and enrichment of microalgae biomass. During the foam flotation process, a foaming agent is added to generate the foam (i.e. stabilize it) and to 
enhance the low hydrophobicity of microalgae cells, as observed by Alkarawi and colleagues in 2018. Bubbles are generated, with different size distributions based on the method used, which attach to the microalgae cells due to differences in the physicochemical properties of the interfaces and cause them to travel up to the surface, where they are recovered in the foamate stream (Alkarawi et al., 2018).

However, the presence of interactions between solid, liquid, and gas phases, in addition to chemicals (surfactants), in foam flotation makes it a very complex process; hence, it is difficult to develop mathematical models for the foam flotation process, unlike for other separation processes, such as distillation (Stevenson and Li, 2014). The availability of a mathematical model for the flotation process is essential for its evaluation, optimization, and automation (Bu et al., 2016b). Consequently, kinetic, probabilistic, and empirical models have been developed to better describe the process. Of these, kinetic models are more popular because they are simple and can reasonably imitate the batch flotation process (Alvarez-Silva et al., 2016).

In general, the flotation kinetics of particles has been developed based on homogenous reaction kinetics, since the collision of chemical molecules in reactions is analogous to the collision of air bubbles with particles in the flotation process. Consequently, many studies have started by employing various reaction kinetic models to better characterize the flotation process. The generalized form of the flotation rate equation is given below (Miettinen et al., 2010; Bu et al., 2016a; Bu et al., 2016b):

$$
\frac{d C}{d t}=-k C^{n}
$$

where $C(\mathrm{mg} / \mathrm{ml})$ is the concentration of valuable particles in the collection zone, $k\left(\mathrm{~min}^{-1}\right)$ is the flotation rate constant, $t$ ( $\mathrm{min}$ ) is the flotation time, and $n$ is the flotation kinetic order. The recovery of particles in the top product (foamate) $(R)$ at any time is defined as:

$$
R(t)=\frac{C_{i}-C(t)}{C_{i}}=1-\frac{C(t)}{C_{i}}
$$

where $C_{i}(\mathrm{mg} / \mathrm{ml})$ is the initial concentration of particles in the bubbly liquid zone. The ultimate recovery (i.e. the maximum recovery, $R_{\infty}$ ) after infinite time is calculated by Equation 2 at $C_{\infty}$ (i.e. the particle concentration in the collection zone at $t_{\infty}$ ) as follows:

$$
R_{\infty}=1-\frac{C_{\infty}}{C_{i}}
$$

When Equations 2 and 3 are substituted into Equation 1, the flotation rate equation based on particle recovery can be obtained, as set out in Equation 4:

$$
\frac{d R}{d t}=K\left(R_{\infty}-R\right)^{n}
$$

To account for the floatability distribution of particles in the collection zone, distributed rate constants are often utilized instead of a single rate constant (Yianatos, 2007). The floatability of particles can be simply defined as the tendency of particles to float or the fraction of floating particles (Runge et al., 2003; Corona-Arroyo et al., 2018), and it is a function of the particle characteristics that affect the flotation rate constant, such as particle size and shape, liberation properties of the particles, hydrophobicity, surface energy, liquid surface tension, and pH (Leroy et al., 2011; Guerrero-Pérez et al., 2017; Xia, 2017; Corona-Arroyo et al., 2018). Particle floatability is not affected by the operational conditions of the flotation process, and this notion was introduced to extend the applicability of flotation kinetic models to account for the heterogeneity of particles $\mathrm{Bu}$ et 
al., 2016a). However, this may not apply to the flotation of microalgae cells, since they have, to a certain extent, a narrow size distribution and similar shapes and surface properties. Nevertheless, some microalgae aggregations resulting from the presence of surfactant have been observed under microscope, with possible simple variations in surface energy and hydrophobicity among microalgae cells during the growth period, which might result in different flotation rates; Equation 4 is therefore written as follows:

$$
\frac{d R}{d t}=f(K)\left(R_{\infty}-R\right)^{n}
$$

In this work, the flotation kinetics of the microalgae Chlorella vulgaris were studied for the first time by performing flotation rate tests to better describe the recovery of microalgae by the flotation process. The recovery of microalgae cells in a batch foam flotation column over time at different operating conditions was fitted to nine flotation kinetic models. The flotation rate tests were carried out at different air flow rates and surfactant concentrations. Cetyltrimethylammonium bromide (CTAB) was used in this work because a previous work demonstrated that it produced the best enhancement of the hydrophobicity of microalgae cells and recovery efficiency (Alkarawi et al., 2018). Other studies have also demonstrated the unique characteristics of CTAB in the removal of microalgae (Laamanen et al., 2016) and the preservation of nanofluid stability during agglomeration and precipitation (Kusrini et al., 2019).

\section{Materials and Methods}

\subsection{Microalgae Culture}

Freshwater Chlorella vulgaris was grown non-sterilely using BG-11 medium in a $20 \mathrm{~L}$ polycarbonate carboy (Nalgene) at $22^{\circ} \mathrm{C}$. Cold and warm fluorescent lights (average illuminance of 2,400 lux) were used, with a light regime of 16L:8D. The agitation of the culture and the gas transfer were facilitated by an aquarium air pump. The culture was maintained semi-continuously.

\subsection{Flotation Tests for Kinetic Study}

The foam flotation column was fabricated from acrylic plastic tubes with an internal diameter of $5 \mathrm{~cm}$ and height of $95 \mathrm{~cm}$ (Figure 1). Compressed air and a sparger were used to generate air bubbles in the column. The sparger was made from UHMWP material with a diameter of $5 \mathrm{~cm}$, a thickness of $1 \mathrm{~cm}$, and a mean pore size of $6 \mu \mathrm{m}$. A magnetic stirrer was used to mix the microalgae culture with the CTAB surfactant (supplied by Sigma Aldrich) for 15 minutes prior to the charging of the mixture to the foam column. The concentration of the microalgae used during all experiments was $0.35 \pm 0.10 \mathrm{~g} \mathrm{~L}^{-1}$ dry basis. This concentration was chosen as it falls within the range of microalgae densities produced by the raceway open pond (Chisti, 2013).

Previous work by Alkarawi et al. (2018) demonstrated that CTAB concentration and air flow rate were the most significant factors affecting the flotation process; consequently, their influences on the flotation kinetics were studied herein using three CTAB concentrations $(20,30$, and $40 \mathrm{mg} / \mathrm{L})$ and two air flow rate magnitudes $(1$ and $2 \mathrm{~L} / \mathrm{min})$, equivalent to superficial gas velocities of 0.008 and $0.017 \mathrm{~m} / \mathrm{s}$, respectively. The column was fabricated with an outlet stream at the base of the column, $1 \mathrm{~cm}$ above the sparger, to discharge the spent culture. Through each experimental trial, the microalgae-CTAB mixture was charged to the column to obtain a liquid depth of $30 \mathrm{~cm}$ before compressed air was introduced through the sparger. The foamate and spent culture samples were collected over time. Each batch flotation test was performed with three replicates. 
The recovery efficiency $(R E \%)$ of microalgae from the culture medium was determined according to Equation 6:

$$
R E \%=\frac{C M_{F}}{C M_{i}} \times 100
$$

where $C M_{F}(\mathrm{mg} / \mathrm{ml})$ is the dry basis concentration of separated microalgae in the top product (foamate) and $C M_{i}(\mathrm{mg} / \mathrm{ml})$ is the initial dry basis concentration of microalgae in the culture. The recovery efficiency based on the concentration of microalgae in the spent culture was also determined for validation purposes (see Equation 2).

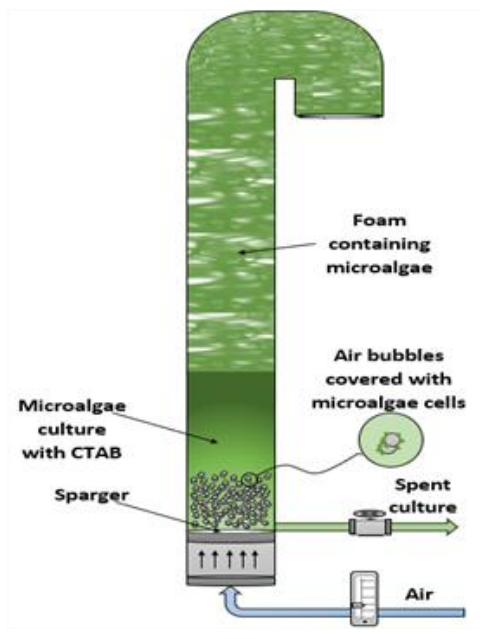

Figure 1 Experimental setup of the batch foam flotation column

The dry basis concentration of microalgae $(M D C)$ was measured using the following steps: a filter paper (Whatman, grade 42 ) was dried at $105^{\circ} \mathrm{C}$ for $5 \mathrm{hrs}$, then held over activated alumina desiccant in a desiccator until use. A precise balance was used to weigh the pre-dried paper prior to the filtration of a known volume (5-10 ml) of microalgae suspension by a vacuum filtration unit. After filtration, the pre-weighed filter paper was dried at $105^{\circ} \mathrm{C}$ overnight, then kept in the desiccator. The dried paper (containing microalgae biomass) was then weighed, and the dry basis concentration of microalgae biomass was determined using Equation 7:

$$
M D C=\frac{w 2-w 1}{v}
$$

where $w 2(\mathrm{mg})$ is the weight of the dried filter paper containing the microalgae, $w 1(\mathrm{mg})$ is the weight of the dried filter paper before filtration, and $v(\mathrm{ml})$ is the volume of the filtered microalgae suspension.

\section{Results and Discussion}

\subsection{Flotation Kinetics and the Optimal Kinetic Model for Microalgae Chlorella Vulgaris}

The study of the kinetic models for flotation processes depends on their similarity with the chemical reaction kinetics. The availability of a mathematical model that integrates both the recovery and the rate constant can completely describe the recovery-flotation time profile, which represents a pivotal tool for assessing the flotation process. In this work, the recovery of microalgae in the foam column over time was fitted to nine flotation kinetic models, including first, fractional, and second order kinetic models, with and without four types of distribution function, including rectangular, exponential, gamma and sinusoidal, in 
addition to fully mixed reactor and modified Kelsall flotation kinetic models. The proposed flotation kinetic models are described in Table 1. All unknown parameters of the kinetic models, such as the ultimate recovery and the rate constant, were estimated after subjecting the flotation rate data to a curve-fitting procedure using the non-linear least squares fitting in MATLAB, R2015a (8.5.0.197613). The validity and variability of the proposed models was then evaluated using two statistical criteria (coefficient of determination $\mathrm{R}^{2}$ with adjusted $\mathrm{R}^{2}$ and mean squared error [MSE]) to determine the optimal kinetic model. These criteria were computed from the experimental and predicted data for flotation recovery, the number of data points, and the number of variables in the kinetic model, using MATLAB's built-in functions. Unlike $\mathrm{R}^{2}$, which often increases if a new term is introduced to the model, either because the new term improves the model or simply by chance, the adjusted $\mathrm{R}^{2}$ increases only if the new term improves the model more than would be expected by chance. The values of $\mathrm{R}^{2}$, adjusted $\mathrm{R}^{2}$, and MSE for the nine kinetic models, in addition to the ultimate recovery and flotation rate constants, are presented in Table S1 (supplementary materials).

Comparisons of the flotation rate data with the different kinetic models at CTAB concentrations of 20,30 , and $40 \mathrm{mg} \mathrm{L}^{-1}$ and air flow rates of 1 and $2 \mathrm{~L} \mathrm{~min}^{-1}$ are shown in Figures 2,3 , and 4 . The maximum flotation time for achieving steady state recovery varied remarkably under different flotation conditions. Swift steady state recovery efficiency was attained at higher air flow rate and surfactant concentration, as shown in Figures $4 \mathrm{a}$ and $4 \mathrm{~b}$. Under all flotation conditions, rapid increases in the recovery of microalgae can be seen at the start of the flotation process. Thereafter, the recovery values show slow increasing tendencies. For instance, in the microalgae flotation test at $40 \mathrm{mg} \mathrm{L}^{-1} \mathrm{CTAB}$ concentration and $2 \mathrm{~L} \mathrm{~min}^{-1}$ air flow rate, more than $70 \%$ recovery was obtained in the first $1.5 \mathrm{~min}$ and $27 \%$ thereafter. Under the experimental flotation conditions, the modified Kelsall model showed a remarkable fit to the experimental flotation rate data, compared to the other models, as shown in the Figures below. First order with gamma distribution and, occasionally, first order with rectangular distribution, second order, and second order with rectangular distribution showed good performances as well.

Table 1 The proposed flotation kinetic models

\begin{tabular}{|c|c|c|c|}
\hline No. & $\begin{array}{l}\text { Kinetic } \\
\text { model }\end{array}$ & Formula & Comment \\
\hline 1. & $\begin{array}{l}\text { First order } \\
\text { model }\end{array}$ & $R=R_{\infty}\left[1-e^{-k t}\right]$ & $\begin{array}{l}\text { In the first order flotation kinetic model, } \\
\text { the number of bubbles is considered to be } \\
\text { much higher than that of microalgae } \\
\text { particles (i.e. constant over time); } \\
\text { consequently, the collision rate between } \\
\text { them is first order with respect to the } \\
\text { number of microalgae particles. It is the } \\
\text { most broadly accepted model and is } \\
\text { regarded as fitting the data well for low } \\
\text { particle recovery (Sutherland, 1948; Bu } \\
\text { et al., 2016a). }\end{array}$ \\
\hline
\end{tabular}

In the second order flotation kinetic model, the number of bubbles is
Second
order
model

$$
R=\frac{R_{\infty}^{2} k t}{1+R_{\infty} k t}
$$
considered to be changing over time. Both the first and second order kinetic models have two parameters that describe the flotation of mono-dispersed particles of a 


\begin{tabular}{|c|c|c|}
\hline No. & $\begin{array}{l}\text { Kinetic } \\
\text { model }\end{array}$ & Formula \\
\hline 3. & $\begin{array}{l}\text { First order } \\
\text { model with } \\
\text { rectangular } \\
\text { distribution }\end{array}$ & $R=R_{\infty}\left\{1-\frac{1}{k t}\left[1-e^{-k t}\right]\right\}$ \\
\hline
\end{tabular}

\section{Second}

order

4. model with rectangular distribution

$$
R=R_{\infty}\left[1-\frac{1}{k t} \ln (1+k t)\right]
$$

constant floatability (Bu et al., 2016a; Bu et al., 2016b).

To extend the flexibility and applicability of the first order kinetic model, the continuous rectangular distribution of floatability was introduced $(\mathrm{Bu}$ et al., 2016a; Bu et al., 2016b).

kinetic model this type of continuous distribution was introduced to extend the second order kinetic model's flexibility and applicability (Bu et al., 2016a; Bu et al., 2016b).

\begin{tabular}{|c|c|c|c|}
\hline 5. & $\begin{array}{l}\text { First order } \\
\text { model with } \\
\text { gamma } \\
\text { distribution }\end{array}$ & $R=R_{\infty}\left[1-\left(\frac{\lambda}{\lambda+t}\right)^{P}\right]$ & $\begin{array}{l}\text { Like the models above, a gamma } \\
\text { distribution function was introduced to } \\
\text { the first order kinetic model to account } \\
\text { for the variability in the kinetic rate } \\
\text { constant (Bu et al., 2016a). }\end{array}$ \\
\hline 6. & $\begin{array}{l}\text { rst order } \\
\text { odel with } \\
\text { lusoidal } \\
\text { stribution }\end{array}$ & $R=R_{\infty}\left[1-\frac{1-2 k t \frac{e^{-k t}}{\pi}}{\left(1+\frac{2 k t}{\pi}\right)^{2}}\right]$ & $\begin{array}{l}\text { The continuous sinusoidal distribution of } \\
\text { floatability was introduced to the first } \\
\text { order kinetic model in } 1992 \text { (Diao et al., } \\
\text { 1992). }\end{array}$ \\
\hline 7. & $\begin{array}{l}\text { Fully mixed } \\
\text { reactor } \\
\text { model }\end{array}$ & $R=R_{\infty}\left[1-\frac{1}{1+t / k}\right]$ & $\begin{array}{l}\text { This type of continuous exponential } \\
\text { distribution of floatability was introduced } \\
\text { by Imaizumi and Inoue in } 1963 \text { to extend } \\
\text { the first order kinetic model's flexibility } \\
\text { and applicability, thus allowing it to fit the } \\
\text { flotation data well (Imaizumi and Inoue, } \\
\text { 1963). }\end{array}$ \\
\hline 8. & $\begin{array}{l}\text { actional } \\
\text { der } \\
\text { odel }\end{array}$ & $R=R_{\infty}\left\{1-\frac{1}{\left[1+0.5 R_{\infty}^{0.5} k t\right]^{2}}\right\}$ & $\begin{array}{l}\text { This kinetic model was described and } \\
\text { employed solely by Horst and Morris } \\
\text { (1956). }\end{array}$ \\
\hline 9. & $\begin{array}{l}\text { Modified } \\
\text { Kelsall } \\
\text { model }\end{array}$ & $\begin{aligned} & R=R_{\infty}[(1-\varphi)\left(1-e^{-k_{f} t}\right) \\
&\left.+\varphi\left(1-e^{-k_{s} t}\right)\right]\end{aligned}$ & $\begin{array}{l}\text { In contrast to the distributions } \\
\text { introduced into the classical first and } \\
\text { second order kinetic models, which are } \\
\text { continuous, this model contains a discrete } \\
\text { distribution of floatability. The modified } \\
\text { version of Kelsall is a first order kinetic } \\
\text { model that integrates two fractions } \\
\text { (essentially defined as slow- and fast- } \\
\text { floating particles); hence, it has two rate } \\
\text { constants instead of one (Bu etal., 2016a). }\end{array}$ \\
\hline
\end{tabular}

In this table, $R$ and $R_{\infty}(\%)$ are the flotation recoveries at any time $t$ and at infinite time $t_{\infty}$, respectively; $k$ is the flotation rate constant $\left(\mathrm{min}^{-1}\right) ; \lambda$ and $P$ are the inverse of the rate constant ( $\mathrm{min}$ ) and exponential number in the first order model with gamma distribution, respectively; $\varphi$ is the fraction of slow-floating particles; and $k_{s}$ and $k_{f}$ are the flotation rate constants of slow- and fast-floating particles, respectively $\left(\mathrm{min}^{-1}\right)$. 


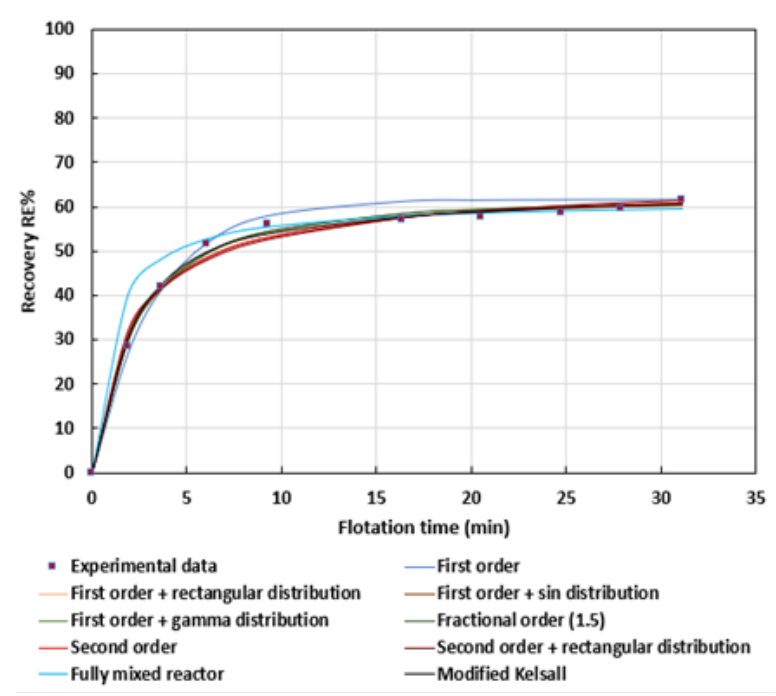

(a)

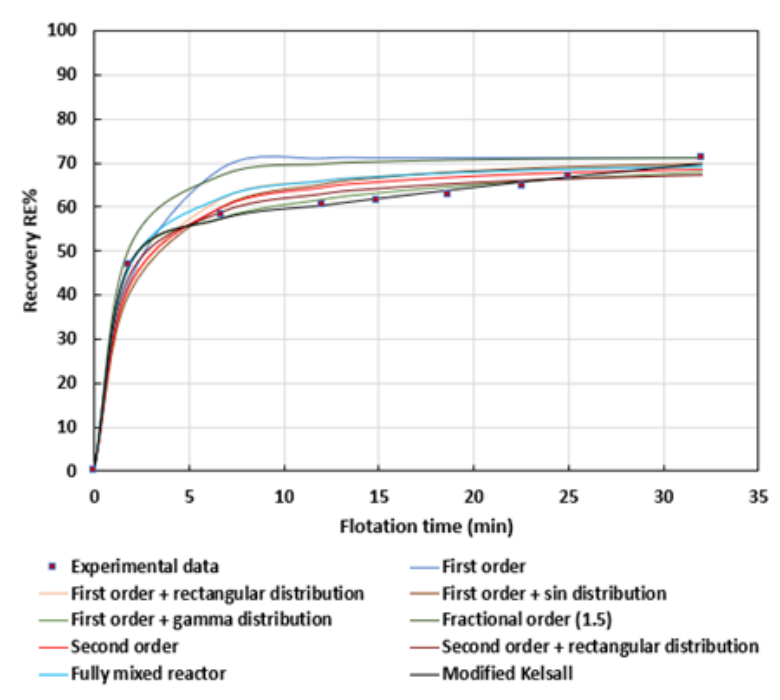

(b)

Figure 2 Comparison of the test results and the proposed kinetic models under flotation conditions of: (a) $20 \mathrm{mg} / \mathrm{L}$ CTAB concentration and air flow rate of $1 \mathrm{~L} / \mathrm{min}$; and (b) $20 \mathrm{mg} / \mathrm{L}$ CTAB concentration and air flow rate of $2 \mathrm{~L} / \mathrm{min}$

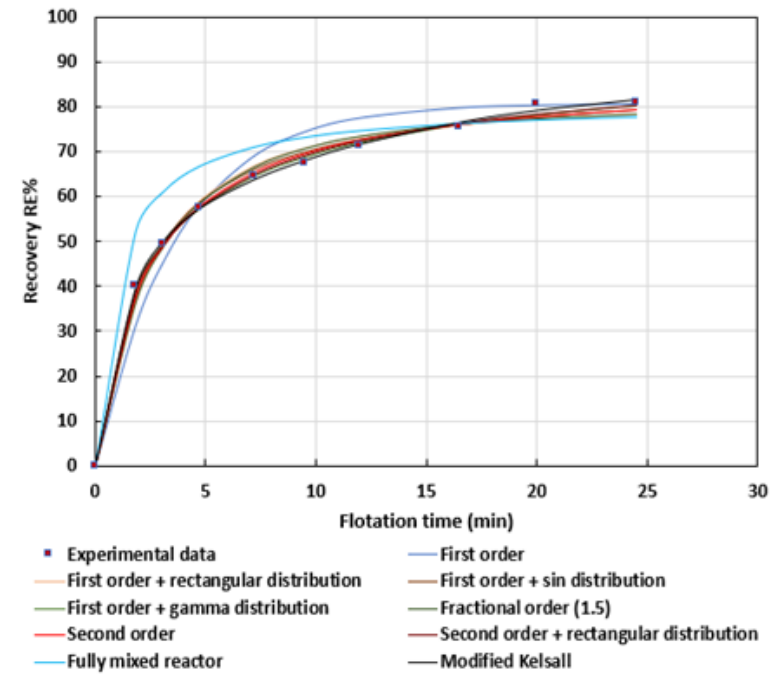

(a)

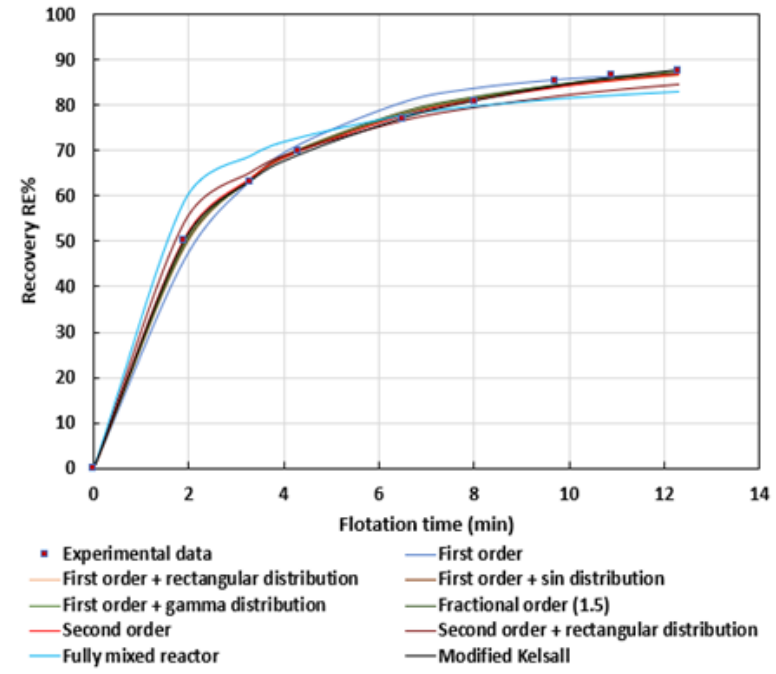

(b)

Figure 3 Comparison of the test results and the proposed kinetic models under flotation conditions of: (a) $30 \mathrm{mg} / \mathrm{L} \mathrm{CTAB}$ concentration and air flow rate of $1 \mathrm{~L} / \mathrm{min}$; and (b) $30 \mathrm{mg} / \mathrm{L} \mathrm{CTAB}$ concentration and air flow rate of $2 \mathrm{~L} / \mathrm{min}$

However, apart from the modified Kelsall model, which has discrete rate constants, no single kinetic model, with or without a continuous distribution, was sufficient to represent the flotation data, and the optimal model may vary under different conditions. For instance, the first order kinetic model with continuous gamma distribution fit the flotation data better than other models with continuous distributions under all flotation conditions except for the flotation test under $20 \mathrm{mg} \mathrm{L}^{-1} \mathrm{CTAB}$ concentration and $1 \mathrm{~L} \mathrm{~min}^{-1}$ air flow rate, for which the first order with rectangular distribution was the most suitable. This outcome was consistent with the conclusions of Dowling et al. (1985). 


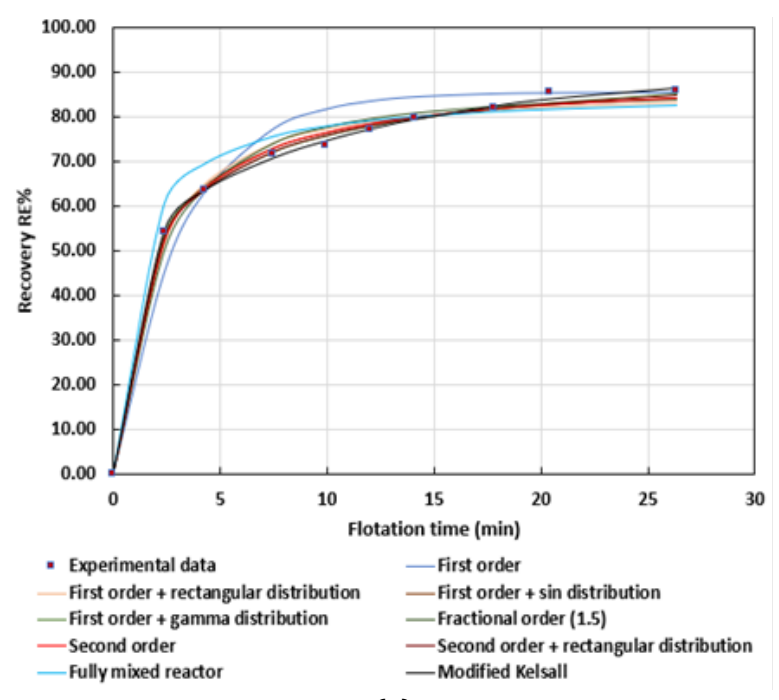

(a)

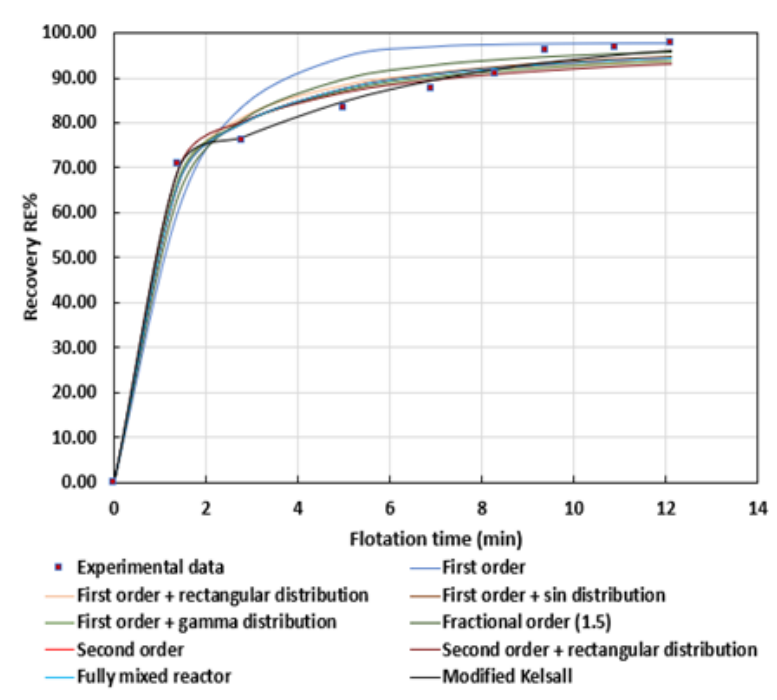

(b)

Figure 4 Comparison of the test results and the proposed kinetic models under flotation conditions of: (a) $40 \mathrm{mg} / \mathrm{L} \mathrm{CTAB}$ concentration and air flow rate of $1 \mathrm{~L} / \mathrm{min}$; and (b) $40 \mathrm{mg} / \mathrm{L} \mathrm{CTAB}$ concentration and air flow rate of $2 \mathrm{~L} / \mathrm{min}$

From Table S1, the modified Kelsall model shows the highest values of adjusted $\mathrm{R}^{2}$ $(>0.995)$ and the lowest values of MSE $(<2.63)$. Therefore, the modified Kelsall model is the optimal kinetic model to characterize the overall flotation process of microalgae. It can be inferred that two-fraction models, such as the modified Kelsall, which has four parameters, correlate better with the flotation rate data of microalgae than other models with two or three parameters, such as second order and first order with gamma distribution kinetic models.

The flotation rate constants of fast-floating particles obtained from the modified Kelsall model were much larger than those of slow-floating particles under various flotation conditions. Different ultimate recovery magnitudes were obtained by fitting the flotation rate data to the modified Kelsall model. The maximum ultimate recovery in the optimal model was $100 \%$ and was obtained under various CTAB concentrations, but only at the higher air flow rate $\left(2 \mathrm{~L} \mathrm{~min}^{-1}\right)$, indicating that the recovery of microalgae strains favors high air flow rates. For flotation tests using a $20 \mathrm{mg} \mathrm{L}^{-1} \mathrm{CTAB}$ concentration and a $1 \mathrm{~L} \mathrm{~min}^{-1}$ air flow rate, the rate constants of fast- and slow-floating particles were $0.5 \mathrm{~min}^{-1}$ and 0.087 $\mathrm{min}^{-1}$, respectively; with a $2 \mathrm{~L} \mathrm{~min}^{-1}$ air flow rate, they were $1.063 \mathrm{~min}^{-1}$ and $0.014 \mathrm{~min}^{-1}$, respectively. Similarly, for flotation tests using a $30 \mathrm{mg} \mathrm{L}^{-1} \mathrm{CTAB}$ concentration and a $1 \mathrm{~L}$ $\mathrm{min}^{-1}$ air flow rate, the rate constants of fast- and slow-floating particles were $0.772 \mathrm{~min}^{-1}$ and $0.087 \mathrm{~min}^{-1}$, respectively; with a $2 \mathrm{~L} \mathrm{~min}^{-1}$ air flow rate, they were $0.897 \mathrm{~min}^{-1}$ and 0.16 $\mathrm{min}^{-1}$, respectively. In other words, the rate constants of fast-floating particles were larger than those of slow-floating particles, indicating that the flotation of the former was rapid and that the slight increase of the surfactant concentration had less effect than the air flow rate on the flotation of slow-floating particles.

\section{Conclusions}

Foam flotation has been shown to be an attractive technique for recovering and concentrating algal biomass from a culture medium. Nevertheless, the development of mathematical models for the foam flotation process is complex, due to the interactions between gas, liquid, and solids phases in the process. Different kinetic models were therefore tested herein to better understand the flotation process of the microalgae cells. 
Nine flotation kinetic models, including single and distributed rate constants as well as a discrete rate constant, were considered because of their trade-offs between accuracy and simplicity. These kinetic equations were used to model the kinetic data of microalgae (Chlorella vulgaris) in the presence of a CTAB surfactant. The regression parameters of the proposed kinetic models were compared to determine the one that fit best.

The four-parameter modified Kelsall kinetic model showed most agreement with the experimental data for the recovery of the microalgae. The maximum recovery predicted by the fitted Kelsall model was $100 \%$ at all CTAB concentrations, but only at the higher air flow rate $\left(2 \mathrm{~L} \mathrm{~min}^{-1}\right)$, indicating that the recovery of microalgae cells is favored at high air flow rates. The flotation of the fast-floating particles was faster than that of slow-floating particles. The air flow rate had larger effect than the slight increase in the surfactant concentration on the flotation of slow-floating particles. These outcomes indicated that the flotation process might require more time or higher air flow rates to increase the recovery of slow-floating particles due to their low flotation rate.

\section{Acknowledgements}

The authors would like to express sincere gratitude to the College of Petroleum Process Engineering, Tikrit University, Iraq, for supporting this work. The authors would also like to extend thanks to Mr. Ayoob Ibrahim and Mr. Omer Ibrahim for their help.

\section{References}

Alkarawi, M.A.S., Caldwell, G.S., Lee, J.G.M., 2018. Continuous Harvesting of Microalgae Biomass using Foam Flotation. Algal Research, Volume 36, pp. 125-138

Alvarez-Silva, M., Vinnett, L., Langlois, R., Waters, K.E., 2016. A Comparison of the Predictability of Batch Flotation Kinetic Models. Minerals Engineering, Volume 99, pp. 142-150

Bu, X., Peng, Y., Ge, L., Ni, C., 2016a. Kinetics of Flotation. Order of Process, Rate Constant Distribution and Ultimate Recovery. Physicochemical Problems of Mineral Processing, Volume 53(1), pp. 342-365

Bu, X., Xie, G., Peng, Y., Chen, Y., 2016b. Kinetic Modeling and Optimization of Flotation Process in a Cyclonic Microbubble Flotation Column using Composite Central Design Methodology. International Journal of Mineral Processing, Volume 157, pp. 175-183

Cercado, A.P., Ballesteros, F.C., Capareda, S.C., 2018. Biodiesel from Three Microalgae Transesterification Processes using Different Homogenous Catalysts. International Journal of Technology, Volume 9(4), pp. 645-651

Chisti, Y., 2013. Constraints to Commercialization of Algal Fuels. Journal of Biotechnology, Volume 167(3), pp. 201-214

Corona-Arroyo, M.A., López-Valdivieso, A., Song, S., 2018. Contact Angle and Vacuum Floatability of Ultrafine Size Particles. Journal of Separation Science and Technology, Volume 53(6), pp. 999-1005

Diao, J., Fuersteenau, D.W., Hanson, J.S., 1992. Kinetics of Coal Flotation. In: SME-AIME Annual Meeting. Phoenix, Arizona, Volume 92

Dowling, E.C., Klimpel, R.R., Aplan, F.F., 1985. Model Discrimination in the Flotation of a Porphyry Copper Ore. Journal of Minerals and Metallurgical Processing, Volume 2, pp. 87-101

Guerrero-Pérez, J.S., Barraza-Burgos, J.M., 2017. A New Mathematical Model for Coal Flotation Kinetics. DYNA Journal, Volume 84, pp. 143-149 
Horst, W.R., Morris, T.M., 1956. Can Flotation Rates Be Improved? Journal of Engineering \& Mining, Volume 157(10), pp. 81-83

Imaizumi, T., Inoue, T., 1963. Kinetic Considerations of Froth Flotation. In: Proceedings of the $6^{\text {th }}$ International Mineral Processing Congress. Cannes, France

Kusrini, E., Putra, N., Siswahyu, A., Tristatini, D., Prihandini, W.W., Alhamid, M.I., Yulizar, Y., Usman, A., 2019. Effects of Sequence Preparation of Titanium Dioxide-water Nanofluid using Cetyltrimethylammonium Bromide Surfactant and $\mathrm{Tio}_{2}$ Nanoparticles for Enhancement of Thermal Conductivity. International Journal of Technology, Volume 10(7), pp. 1453-1464

Laamanen, C.A., Ross, G.M., Scott, J.A., 2016. Flotation Harvesting of Microalgae. Renewable and Sustainable Energy Reviews, Volume 58, pp. 75-86

Leroy, S., Dislaire, G., Bastin, D., Pirard, E., 2011. Optical Analysis of Particle Size and Chromite Liberation from Pulp Samples of a UG2 Ore Regrinding Circuit. Minerals Engineering, Volume 24(12), pp. 1340-1347

Miettinen, T., Ralston, J., Fornasiero, D., 2010. The Limits of Fine Particle Flotation. Minerals Engineering, Volume 23(5), pp. 420-437

Rizaldi, M.I., Rahman, A., Deendarlianto, A., Prihantini, N.B., Nasruddin, N., 2019. Generation of Microbubbles through Single Loop and Double Loop Fluid Oscillator for Photobioreactor Aeration. International Journal of Technology, Volume 10(7), pp. 1446-1452

Runge, K.C., Franzidis, J.P., Manlapig, E., 2003. A Study of the Flotation Characteristics of Different Mineralogical Classes in Different Streams of an Industrial Circuit. In: Proceedings of the XXII International Mineral Processing Congress. Cape Town, South Africa, pp. 962-972

Stevenson, P., Li, X., 2014. Foam Fractionation: Principles and Process Design $\left(1^{\text {st }} \mathrm{ed}\right)$. Taylor $\&$ Francis Group, CRC Press, Boca Raton

Sukarni, S., Sumarli, S., Nauri, I.M., Prasetiyo, A., Puspitasari, P., 2019. Thermogravimetric Analysis on Combustion Behavior of Marine Microalgae Spirulina Platensis Induced by $\mathrm{MgCO}_{3}$ and $\mathrm{Al}_{2} \mathrm{O}_{3}$ Additives. International Journal of Technology, Volume 10(6), pp. 1174-1183

Sutherland, K.L., 1948. Physical Chemistry of Flotation. XI. Kinetics of the Flotation Process. The Journal of Physical and Colloid Chemistry, Volume 52(2), pp. 394-425

Xia, W., 2017. Role of Particle Shape in the Floatability of Mineral Particle: An Overview of Recent Advances. Powder Technology, Volume 317, pp. 104-116

Yianatos, J.B., 2007. Fluid Flow and Kinetic Modelling in Flotation Related Processes. Journal of Chemical Engineering Research and Design, Volume 85(12), pp. 1591-1603 